\title{
Use of Professionally Administered Topical Fluorides in Asia
}

\section{E.C.M. Lo ${ }^{1 *}$, L.M.A. Tenuta ${ }^{2}$, and C.H. Fox ${ }^{3}$}

${ }^{1}$ Faculty of Dentistry, The University of Hong Kong, Hong Kong SAR, China; ${ }^{2}$ Piracicaba Dental School, University of Campinas, Piracicaba, SP, Brazil; and ${ }^{3}$ International Association for Dental Research, Alexandria, VA, USA; *corresponding author, 3/F, Prince Philip Dental Hospital, 34 Hospital Road, Hong Kong, edward-lo@hku.hk

Adv Dent Res 24(1):11-15, 2012 topical fluorides are used in addition to fluoride toothpaste, there is a modest reduction in caries of around $10 \%$ compared with that achieved with toothpaste use alone (Marinho et al., 2004b). The recommended use of professionally administered topical fluoride and the frequency of application depend on the assessed dental caries risk of the individual or population-i.e., higher frequency of application for people with higher caries risk, longer time interval for people with moderate risk - and the use is not necessary in people with low risk (ADA Council on Scientific Affairs, 2006; Chu et al., 2010).

In Asia, large differences in the economic development of the various countries and also in the health status of their populations can be observed (World Bank, 2011; World Health Organization, 2011). Similarly, great diversities exist regarding the dental caries situation of children and adults, with countries being classified as high level, such as the Philippines, through moderate level, such as South Korea, to low level, such as India, and to very low level, such as China (Petersen, 2003). Asian countries also vary in their approaches to control caries, at either the individual or the population level.

The aim of this paper is to describe the current situation of the use of professionally administered topical fluorides in various Asian countries, discussing the barriers and perspectives for their implementation as an effective caries preventive approach. A description of the use of self-applied topical fluorides in Asia can be found in a paper by Zero et al. (2012).

\section{PROFESSIONALLY APPLIED FLUORIDES}

\section{Fluoride Gel/Foam}

Different fluoride compounds have been used in fluoride gels for years. Sodium fluoride can be used in a neutral $\mathrm{pH}$ environment or can be acidulated and buffered with a phosphate to form acidulated phosphate fluoride (APF). Clinical use of APF was developed in the 1960s, and the concentration commonly used in fluoride gel today is $1.23 \%$ (Newbrun, 2011). In the application, a sufficient amount of gel to cover the teeth in a dental arch is dispensed into a disposable tray and inserted into the mouth. The recommended application time is $4 \mathrm{~min}$, and the patient should expectorate the gel afterward (Hawkins et al., 2003).

A Cochrane systematic review of fluoride gel found good evidence to support its dental caries-preventive effect (Marinho

\section{Key Words}

dental caries, fluoride, Asian, preventive dentistry, dentists, dental health services.

(C) International \& American Associations for Dental Research 
et al., 2003b). The weighted mean reduction in DMFS increment in the permanent teeth of children in the 14 placebo-controlled clinical trials included in the meta-analysis was $21 \%$. However, little information on its effectiveness in the primary dentition of young children is available. Because a relatively large amount of fluoride is present in the gel delivered in a tray, risk of excessive ingestion by young children, leading to mild toxic side-effects, is a potential problem for its use (Adair, 2006).

The content and usage of fluoride foam are similar to those of fluoride gel. Since the amount of fluoride in the foam dispensed into a mouth tray is much less than that in gel form, the risk of excessive fluoride ingestion by young children is much lower. However, little information from clinical trials on its effectiveness in caries prevention is available.

\section{Fluoride Varnish}

Fluoride varnish is a non-aqueous form of topical fluoride and was developed in the 1960 s to promote a longer retention of the fluoride agent on tooth surfaces (Chu and Lo, 2006). It is quick and easy to apply directly onto tooth surfaces with a mini-brush. It adheres to tooth surfaces even in the presence of saliva. Several compounds, including difluorosilane and sodium fluoride, have been used at different concentrations, but the moststudied varnishes contain 5\% sodium fluoride in an alcoholic solution of natural varnish substances.

Results of the meta-analysis of pooled data from 7 clinical studies in a Cochrane systematic review of fluoride varnish showed an average reduction of $46 \%$ and $33 \%$ in caries increment in the permanent and primary teeth of children, respectively (Marinho et al., 2002). Advantages of using fluoride varnish include its safety and ability to be applied to specific tooth surfaces or sites with higher caries risk. The amount of fluoride applied is controlled by the operator, making it safe for use in young children below the age of 6 years (Miller and Vann, 2008) and appropriate for people with special needs (Weintraub, 2003).

Clinical studies have shown that fluoride varnish application can prevent caries in the pits and fissures of permanent molars (Hawkins et al., 2003). However, in a recent Cochrane systematic review, no conclusion could be drawn as to whether it can serve as an alternative prevention method to fissure sealant placement (Hiiri et al., 2010). Besides preventing new dental caries, regular applications of fluoride varnish to active caries lesions can lead to remineralization and caries arrest in children (Chu et al., 2002). A practical problem with promoting the use of fluoride varnish is its higher material cost per application to multiple teeth compared with that of other topical fluoride therapies, such as fluoride foam (Hawkins et al., 2004).

\section{Fluoride Solution}

Topical application of concentrated sodium fluoride or stannous fluoride solution was practiced in the US some decades ago, but, because of safety concerns, this is no longer common (Chu et al., 2010). Application of silver fluoride or silver diamine fluoride (SDF) solution at concentrations of 38 to $40 \%$ to arrest active cavitated caries lesions in primary teeth has been practiced in Australia and Japan for many years (Chu and Lo, 2008).
A recent systematic review found that a prevented fraction of around $70 \%$ for new caries in both primary and permanent teeth in children can be obtained through applications of SDF solution, and the success rate for caries arrest can be over $90 \%$ (Rosenblatt et al., 2009). Similar effects on root-surface caries in elders have also been reported (Tan et al., 2010).

Usually, a disposable micro-applicator is used to apply a small amount of SDF solution directly onto a caries lesion or a caries-susceptible tooth site. It has an unpleasant metallic taste, but this is only transient. It will not stain sound tooth surfaces, but the arrested caries lesion usually appears black. Despite these disadvantages, its significant effectiveness in arresting active dentin caries lesions makes SDF a valuable agent for caries arrest treatment, for managing caries in the primary teeth of young children who are less cooperative, and in field settings (Chu et al., 2002; Llodra et al., 2005).

\section{PROFESSIONAL FLUORIDE USE IN VARIOUS COUNTRIES IN ASIA}

Information in this section was provided by the participants of two discussion sessions in the workshop on "Effective use of fluoride in Asia" held in Phang-Nga, Thailand, in March 2011, and also extracted from the country reports in the workshop proceedings (Siriphant and Srisawasdi, 2011). These participants were mostly representatives of the government ministry of health or national dental association of selected countries in East and South Asia.

There is great diversity in the use of professionally administered topical fluorides in different countries in Asia. In the highand upper-middle-income countries (World Bank, 2011), application of fluoride varnish and gel is common among dental professionals (Table 1).

In Brunei, a small independent sultanate in Borneo with an oil-exportation-based economy, 5\% sodium fluoride varnish is applied twice yearly onto the permanent teeth of primary school children in a school-based program. The program was started in 2010 to cover grade 1 students and will develop incrementally to cover other grades.

In Japan, application of APF gel (9000 ppm) is common for children. There is a long history of development of a policy and guidelines for fluoride use in Japan. In most of the prefectures and municipal cities, there are health programs involving the use of fluorides. Most (70-80\%) of the children aged 4 years and above have received topical fluoride applications. In addition, SDF solution is used in dental clinics to arrest dental caries in children.

In Malaysia, where there is a heavily subsidized public dental service, free basic oral care services are provided in public dental clinics to preschool and school-aged children up to the age of 17 years. Fluoride varnish is applied by dental therapists in schools and health centers and is advocated for use in preschool children to prevent dental caries. A systematic fluoride varnish program has been developed as an integral part of the Early Childhood Oral Healthcare program and is being tested in four states.

In Hong Kong and in Singapore, fluoride varnish and gel are commonly used in both public and private dental clinics. In 
Table 1. Use of Professionally Applied Sodium Fluoride Varnish, Fluoride Gel/Foam, and Silver Fluoride Solution in Some High- and Upper-middle-income Asian Countries/Areas

\begin{tabular}{|c|c|c|c|}
\hline & Fluoride Varnish & Fluoride Gel/Foam & Silver Fluoride Solution \\
\hline Brunei & $\begin{array}{l}\text { Use in public service for caries } \\
\text { prevention in schoolchildren and } \\
\text { toddlers }\end{array}$ & No information & No information \\
\hline Hong Kong, China & $\begin{array}{l}\text { Use in both private and public } \\
\text { service }\end{array}$ & $\begin{array}{l}\text { Use in both private and public } \\
\text { service }\end{array}$ & $\begin{array}{l}\text { Use in some private clinics; in } \\
\text { community projects for preschool } \\
\text { children and elders }\end{array}$ \\
\hline Japan & Use in private clinic & $\begin{array}{l}\text { Use in both private and public } \\
\text { service; commonly used in health } \\
\text { promotion programs }\end{array}$ & $\begin{array}{l}\text { Use in clinics to prevent and arrest } \\
\text { caries }\end{array}$ \\
\hline Malaysia & $\begin{array}{l}\text { Use in both private and public } \\
\text { service; pilot test for use in public } \\
\text { service for prevention of early } \\
\text { childhood caries }\end{array}$ & $\begin{array}{l}\text { Use in both private and public } \\
\text { service }\end{array}$ & Not available \\
\hline South Korea & Use in private clinic & Use in private clinic & Not available \\
\hline Singapore & $\begin{array}{l}\text { Use in both private and public } \\
\text { service }\end{array}$ & $\begin{array}{l}\text { Use in both private and public } \\
\text { service }\end{array}$ & Not available \\
\hline
\end{tabular}

Table 2. Use of Professionally Applied Sodium Fluoride Varnish, Fluoride Gel/Foam, and Silver Fluoride Solution in Some Low- and Lower-middle-income Asian Countries/Areas

\begin{tabular}{|c|c|c|c|}
\hline & Fluoride Varnish & Fluoride Gel/Foam & Silver Fluoride Solution \\
\hline China (Mainland) & $\begin{array}{l}\text { Limited use in both private and public } \\
\text { clinics }\end{array}$ & $\begin{array}{l}\text { Limited use in both private and public } \\
\text { clinics }\end{array}$ & Not available \\
\hline Laos & $\begin{array}{l}\text { Very limited use in some private } \\
\text { clinics }\end{array}$ & $\begin{array}{l}\text { Very limited use in some private } \\
\text { clinics }\end{array}$ & Not available \\
\hline Mongolia & Use in private clinic & $\begin{array}{l}\text { Use in private clinic; use in } \\
\text { iontophoresis }\end{array}$ & Use in private clinic \\
\hline Myanmar & $\begin{array}{l}\text { Very limited use in some private } \\
\text { clinics }\end{array}$ & $\begin{array}{l}\text { Very limited use in some private } \\
\text { clinics }\end{array}$ & Not available \\
\hline Thailand & $\begin{array}{l}\text { Use in both private and public } \\
\text { service; recommended for children } \\
\text { under age } 3 \text { years; pilot test for } \\
\text { control of root caries }\end{array}$ & $\begin{array}{l}\text { Use in both private and public } \\
\text { service; recommended for children } \\
\text { age } 3 \text { years and above }\end{array}$ & Not available \\
\hline
\end{tabular}

Hong Kong, SDF solution is also used in some community dental projects to arrest active dentinal caries in preschool children and in institutionalized elders. In South Korea, where dental care service is mainly delivered in the private sector, topical application of fluoride varnish and gel is common.

In contrast, the use of professionally administered topical fluorides is not common in the low- and lower-middle-income Asian countries (Table 2). Silver fluoride solution is hardly ever used in these countries. In Bhutan, India, Laos, and Myanmar, fluoride varnish or gel application is available only in some private dental clinics. The situation is similar in Indonesia, Mongolia, Nepal, and the Philippines, where topical fluoride application is performed only in private dental clinics. In Cambodia, fluoride varnish, gel, and solution are mainly brought in by non-governmental organizations and used in their dental clinics or services for children. 
On the Chinese mainland, topical application of fluoride varnish and gel is available in both private and public dental clinics. However, since dental patient visits are mainly symptomdriven and treatment-oriented, the demand for such dental caries-preventive services is low. No organized public dental program using these fluoride agents is available.

In Sri Lanka, application of fluoride varnish and gel is available in private dental clinics. Fluoride varnish is also used in a pilot community health project for toddlers. An oral health policy on the appropriate use of fluorides is being drafted, and provision of topical fluoride free of charge in government dental clinics and by school dental therapists is proposed.

In Thailand, fluoride varnish and gel are used in both private and public dental services. A national guideline on the use of fluorides is being developed. Application of 5\% sodium fluoride varnish is indicated for children with moderate to high caries risk and is recommended for use in children under 3 years of age, and in those who do not cooperate with fluoride gel application. Fluoride varnish application is also included in the benefit package of some projects for preschool children. Fluoride gel application is used in a clinical setting and is recommended for children age 3 years or above who are at moderate to high caries risk.

\section{BARRIERS AND PERSPECTIVES}

With the increased use of topical fluorides in young children, there are concerns about possible adverse side-effects, in particular the development of dental fluorosis. A recent Cochrane systematic review found weak evidence that children starting to use fluoride toothpaste under 12 months of age may have increased risk of mild fluorosis, but drew no conclusion regarding the risk of using other types of topical fluorides, due to lack of information (Wong et al., 2010).

The use of professionally administered topical fluorides depends on the availability of trained dental personnel and is a relatively costly approach to prevent dental caries at a community level. In most of the low- and lower-middle-income countries in Asia, the dental workforce is small relative to population size. The dentist-to-population ratio is usually less than 1:10,000 (Beaglehole et al., 2009), and the figure is particularly low in rural areas. In these countries, formally trained dental auxiliary personnel, such as dental hygienists and therapists, are either not available or exist in only small numbers. The lack of an adequate dental workforce and a well-developed dental care delivery system seriously limits the use of professionally administered fluorides to prevent dental caries.

Since the application of topical fluoride agents is simple, safe, and does not require special dental equipment, it is possible to train local primary healthcare workers or school health personnel to carry out this procedure. However, whether this will infringe on local legal restrictions on who can provide dental care in the community will vary between countries and must be investigated.

In Asian countries, fluoride varnish and gel are usually imported products. The material cost is relatively high, especially in low-income countries. This creates a barrier for the use of these agents. Fluoride varnish, being easy to apply and safe, has been the preferred agent for prevention of the early childhood caries that is prevalent in many developing countries in Asia. Several Southeast Asian countries are adopting or pilot-testing its use in public health programs for toddlers and preschool children. However, fluoride varnish is one of the more expensive topical fluoride agents. The development and production of low-cost fluoride varnishes locally will greatly help to promote this effective cariespreventive method. Exemption from import and sales taxes, if any, will also help to lessen the problem.

The use of professionally applied topical fluorides may not be justified for people with low dental caries risk, especially when they are exposed to fluorides from other sources such as water, milk, or salt fluoridation or from the regular use of fluoridated toothpaste. To achieve high cost-effectiveness, these topical fluoride agents should be used in people with moderate to high caries risk and should be applied to specific high-cariesrisk tooth sites. This will require the concurrent use of a highly sensitive and specific caries risk assessment system or tool for identification of the high-risk population. However, no single system has been shown to be valid and reliable (ADA Council on Scientific Affairs, 2006). Further research and development of a valid caries risk assessment method that is also simple and inexpensive to carry out would greatly benefit the targeted use of professionally applied topical fluorides.

\section{CONCLUSION}

Professionally applied topical fluoride varnish, gel, and solution have been shown to be effective in preventing and in arresting dental caries. These are used in most Asian countries, but their relatively high cost and the shortage of a dental workforce, especially in lower-income countries, hamper the widespread adoption of this method in the private and public dental services. Government health policies should be pursued to lower the cost of treatment, either through incentives for local production and/ or elimination of taxes and tariffs on imported fluoride products.

\section{ACKNOWLEDGMENTS}

We acknowledge the participants of the workshop on "Effective use of fluoride in Asia" held in Phang-Nga, Thailand, in March 2011, for providing information on the use of fluorides in their countries. The author(s) received no financial support and declare no potential conflicts of interest with respect to the authorship and/or publication of this article.

\section{REFERENCES}

Adair SM (2006). Evidence-based use of fluoride in contemporary pediatric dental practice. Pediatr Dent 28:133-142.

American Dental Association Council on Scientific Affairs (2006). Professionally applied topical fluoride evidence-based clinical recommendations. J Am Dent Assoc 137:1151-1159.

Beaglehole R, Benzian H, Crail J, Mackay J, editors (2009). The oral health atlas. Cointrin, Switzerland: FDI World Dental Federation.

$\mathrm{Chu} \mathrm{CH}$, Lo EC (2006). A review of sodium fluoride varnish. Gen Dent 54:247-253.

Chu CH, Lo EC (2008). Promoting caries arrest in children with silver diamine fluoride: a review. Oral Health Prev Dent 6:315-321. 
Chu CH, Lo EC, Lin HC (2002). Effectiveness of silver diamine fluoride and sodium fluoride varnish in arresting dentin caries in Chinese preschool children. $J$ Dent Res 81:767-770.

Chu CH, Mei ML, Lo EC (2010). Use of fluorides in dental caries management. Gen Dent 58:37-43.

Hawkins R, Locker D, Noble J, Kay EJ (2003). Prevention. Part 7: professionally applied topical fluorides for caries prevention. $\mathrm{Br}$ Dent $J$ 195:313-317.

Hawkins R, Noble J, Locker D, Wiebe D, Murray H, Wiebe P, et al. (2004). A comparison of the costs and patient acceptability of professionally applied topical fluoride foam and varnish. J Public Health Dent 64:106-110.

Hiiri A, Ahovuo-Saloranta A, Nordblad A, Mäkelä M (2010). Pit and fissure sealants versus fluoride varnishes for preventing dental decay in children and adolescents. Cochrane Database Syst Rev 3:CD003067.

Llodra JC, Rodriguez A, Ferrer B, Menardia V, Ramos T, Morato M (2005). Efficacy of silver diamine fluoride for caries reduction in primary teeth and first permanent molars of schoolchildren: 36-month clinical trial. $J$ Dent Res 84:721-724.

Marinho VC, Higgins JP, Logan S, Sheiham A (2002). Fluoride varnishes for preventing dental caries in children and adolescents. Cochrane Database Syst Rev 3:CD002279.

Marinho VCC, Higgins JP, Logan S, Sheiham A (2003a). Topical fluoride (toothpastes, mouthrinses, gels or varnishes) for preventing dental caries in children and adolescents. Cochrane Database Syst Rev 4:CD002782.

Marinho VC, Higgins JP, Logan S, Sheiham A (2003b). Systematic review of controlled trials on the effectiveness of fluoride gels for the prevention of dental caries in children. $J$ Dent Educ 67:448-458.

Marinho VC, Higgins JP, Sheiham A, Logan S (2004a). One topical fluoride (toothpastes, or mouthrinses, or gels, or varnishes) versus another for preventing dental caries in children and adolescents. Cochrane Database Syst Rev 1:CD002780.

Marinho VC, Higgins JPT, Sheiham A, Logan S (2004b). Combinations of topical fluoride (toothpastes, mouthrinses, gels, varnishes) versus single topical fluoride for preventing dental caries in children and adolescents. Cochrane Database Syst Rev 1:CD002781.
Miller EK, Vann WF Jr (2008). The use of fluoride varnish in children: a critical review with treatment recommendations. J Clin Pediatr Dent 32:259-264.

Newbrun E (2011). Finn Brudevold: discovery of acidulated phosphate fluoride in caries prevention. $J$ Dent Res 90:977-980.

Petersen PE (2003). The World Oral Health Report 2003: continuous improvement of oral health in the 21 st century - the approach of the WHO Global Oral Health Programme. Community Dent Oral Epidemiol 31(Suppl 1):3-23.

Petersen PE, Lennon MA (2004). Effective use of fluorides for the prevention of dental caries in the 21 st century: the WHO approach. Community Dent Oral Epidemiol 32:319-321.

Petersen PE, Kwan S, Zhu L, Zhang BX, Bian JY (2008). Effective use of fluorides in the People's Republic of China - a model for WHO Mega Country initiatives. Community Dent Health 25(4 Suppl 1):257-267.

Rosenblatt A, Stamford TC, Niederman R (2009). Silver diamine fluoride: a caries "silver-fluoride bullet". J Dent Res 88:119-125.

Siriphant P, Srisawasdi S, editors (2011). Proceedings of the workshop on "Effective use of fluoride in Asia". Bangkok: The Dental Association of Thailand and the Thammasat University, pp. 53-179.

Tan HP, Lo EC, Dyson JE, Luo Y, Corbet EF (2010). A randomized trial on root caries prevention in elders. J Dent Res 89:1086-1090.

Weintraub JA (2003). Fluoride varnish for caries prevention: comparisons with other preventive agents and recommendations for a communitybased protocol. Spec Care Dentist 23:180-186.

Wong MC, Glenny AM, Tsang BW, Lo EC, Worthington HV, Marinho VC (2010). Topical fluoride as a cause of dental fluorosis in children. Cochrane Database Syst Rev 1:CD007693.

World Bank (2011). Data - countries and economies. URL accessed on 10/4/11 at: http://data.worldbank.org/country/.

World Health Organization (2011). Global Health Observatory - country statistics. URL accessed on 10/4/11 at: http://www.who.int/gho/en/.

Zero DT, Marinho VC, Phantumvanit P (2012). Effective use of self-care fluoride administration in Asia. Adv Dent Res 24:16-21. 